\title{
Oxidative stress may explain how hypertension is maintained by normal levels of angiotensin II
}

J.C. Romero ${ }^{1}$ and J.F. Reckelhoff ${ }^{2}$

\section{Correspondence \\ J.C. Romero \\ Department of Physiology \\ Mayo Clinic \\ Rochester, MN 55905 \\ USA \\ Fax: + 1-507-284-8566}

Presented at the III International Symposium on Vasoactive Peptides, Belo Horizonte, MG, Brasil,

October 8-10, 1999.

Research supported by the National Institutes of Health (grant HL16496),

Mayo Foundation, the American Heart Association (grant 9740007N), National Institutes of Health Program Project (grant HL51971) and a grant from Fundacion Barcelo, Argentina.

Received November 26, 1999 Accepted February 2, 2000

\author{
${ }^{1}$ Department of Physiology and Biophysics, Mayo School of Medicine and \\ Division of Hypertension, Mayo Clinic, Rochester, MN, USA \\ ${ }^{2}$ Department of Physiology and Biophysics and the Center for Excellence in \\ Cardiovascular-Renal Research, University of M ississippi Medical Center, \\ Jackson, MS, USA
}

\section{Abstract}

It is well known that essential hypertension evolves in most patients with "near normal" levels of plasma renin activity. However, these levels appear to be responsible for the high levels of arterial pressure because they are normalized by the administration of angiotensin II converting inhibitors or angiotensin receptor antagonist. In experimental animals, hypertension can be induced by the continuous intravenous infusion of small doses of angiotensin II that are not sufficient to evoke an immediate pressor response. However, this condition resembles the characteristics of essential hypertension because the high levels of blood pressure exist with normal plasma levels of angiotensin II. It is suggested that small amounts of angiotensin whose plasma levels are inappropriate for the existing size of extracellular volume stimulate oxidative stress which binds nitric oxide forming peroxynitrite. The latter compound oxidizes arachidonic acid producing isoprostaglandin $\mathrm{F} 2 \alpha$ (an isoprostane) which is characterized by a strong antinatriuretic vasoconstrictor renal effect. In this chain of reactions the vasoconstrictor effects derived from oxygen quenching of nitric oxide and increased isoprostane synthesis could explain how hypertension is maintained with normal plasma levels of renin.

\section{Key words}

- Nitric oxide

- Isoprostanes

- Peroxynitrites

- Essential hypertension

\section{Introduction}

Essential hypertension is one of the most prevalent diseases in western societies (1). Although the pathogenesis of this disease has remained so far elusive (1), there is general agreement that the disease is related to renal dysfunction and that such a dysfunction is mainly characterized by inappropriate circulating levels of renin. This assumption is based first on the efficacy of converting enzyme inhibitors or angiotensin receptor antagonists in reducing blood pressure in essential hyper- tension (2,3), and second, hypertension can be induced in normotensive humans or animals by transplantation of the kidney from hypertensive subjects (2). Alternatively, hypertension can also be cured by transplanting the kidney from normotensive donors into a previously hypertensive individual (2). One of the major stumbling blocks explaining the role played by these two elements, the kidney and renin, in the pathogenesis of essential hypertension is that the levels of circulating plasma renin are within the normal range in most essential hypertensives (3). 
The vasoconstrictor effects of normal levels of angiotensin

To a large extent, one can suggest that the "normal" levels of plasma renin activity observed in most patients with essential hypertension are not normal but inappropriate with respect to the levels of blood pressure (3-5). In fact, if systemic pressure is elevated and renal perfusion pressure increases, the release of renin is immediately suppressed (3). This observation leads to the question on the extent to which hypertension can be induced by "inappropriate" levels of renin. Such a postulate was first supported by the observation of Dickinson et al. (6) who demonstrated in 1963 in rabbits that the infusion of a very small amount of angiotensin II (ang II) that was not sufficient to elicit an immediate elevation of blood pressure produced nonetheless chronic hypertension. This led to the proposal of a new modality of a vasoconstrictor effect produced by angiotensin called slow responses to ang II $(7,8)$. It should be clarified that the fast pressor responses are produced by relatively high concentrations of angiotensin II which induce rapid smooth muscle contraction when administered as a bolus $(9,10)$. The response reaches the maximal pressor response in seconds and returns to normal levels in 2-3 $\mathrm{min}$. The slow pressor response needs $5-10 \mathrm{~h}$ to develop, reaching a maximum peak 3-5 days after the onset of the infusion (8). The important characteristic of the slow pressor response is that it is not specific for any particular animal species since it has been demonstrated in man (11), rats (12), rabbits (6), and dogs (7). In our laboratory we have demonstrated similar responses in the swine model (13). Also, it appears that the slow pressor response evolves at doses of angiotensin that are insufficient not only to produce an immediate elevation of blood pressure but also to stimulate steroidogenic and dipsogenic actions typical of blood-borne angiotensin $(12,14)$. The consistent delayed action of small subpressor doses of angiotensin in producing an increase in blood pressure suggests that there is a time requirement for the activation of additional vasoconstrictor processes which can then trigger an autocatalytic action accelerating or potentiating the vasoconstrictor effect of ang II. For example, Brown et al. (12) demonstrated in rats that the administration of $20 \mathrm{ng} \mathrm{kg}^{-1} \mathrm{~min}^{-1}$ of ang II did not alter blood pressure during the first hour of infusion but on the morning of the following day there was a significant increase by $14 \mathrm{mmHg}$. On day 7 blood pressure had reached $153 \pm 6 \mathrm{mmHg}$. In a study conducted in a separate group of animals, this investigator showed that the amount of angiotensin to be infused for one hour to achieve a comparable level of blood pressure was $279 \mathrm{ng} \mathrm{kg}^{-1} \mathrm{~min}^{-1}$. In these studies, the circulating levels of ang II on day 7 of infusion of $20 \mathrm{ng} \mathrm{kg}^{-1} \mathrm{~min}^{-1}$ were $230 \mathrm{pg} / \mathrm{ml}$, which is not much different from the $150 \mathrm{pg}$ found in animals during the infusion of $20 \mathrm{ng}$ $\mathrm{kg}^{-1} \min ^{-1}$ for one hour when blood pressure was still normal. In contrast, the level of ang II found in acute animals $(146 \pm 3 \mathrm{mmHg})$ infused with $270 \mathrm{ng} \mathrm{kg}^{-1} \mathrm{~min}^{-1}$ for one hour was approximately $2500 \mathrm{pg} / \mathrm{ml}$. This study showed that a small amount of angiotensin could trigger a delayed mechanism that produced vasoconstriction or alternatively potentiated ang II leading to hypertension. In an extensive review on this subject, Lever (8) ruled out the participation of other mechanisms such as the central nervous system, vascular hypertrophy, etc. In this survey, we will examine the possibility that the slow responses to ang II may be due to a vasoconstrictor effect of oxidative stress.

\section{Role of ang II, oxidative stress, nitric oxide, and isoprostanes in the slow responses to ang II}

Ang II has been shown to stimulate the production of superoxide that quenches nitric oxide (NO) $(15,16)$. It is known, on the 
other hand, that the chemical combination of superoxide with $\mathrm{NO}$ yields peroxynitrite (16) which is a potent oxidant that could oxidize arachidonic acid, releasing a potent renal vasoconstrictor, antinatriuretic substance, 8 isoprostaglandin $\mathrm{F}_{2 \alpha}$ (an isoprostane). This sequence of events is illustrated in Figure 1 (16). Additionally, ang II may also stimulate endothelin (ET) synthesis (17-19) which can be further increased by the oxidative stress cascade mentioned above (20-23). Therefore, the reduced levels of $\mathrm{NO}$, increased isoprostane and increased ET represent potent vasoconstrictor effects which can enhance the vasopressor action of ang II and may explain how hypertension is maintained in pathological situations (such as two kidney, one clip Goldblatt hypertension or essential hypertension) where the levels of angiotensin are frequently found to be normal (24). The importance of these pathogenic events is that in the future the clinician may have a better index of the damage produced by hypertension with inappropriate levels of renin by measuring products of oxidative stress rather than the level of plasma renin activity. Oxidative stress has been shown to produce hypertension and renal damage $(25,26)$.

\section{Oxidative stress}

Pryor et al. (16) have shown that oxygen free radicals (superoxide) are constantly being combined with $\mathrm{NO}$, forming peroxynitrite, which is in equilibrium with peroxynitrous acid (superoxide- $+\mathrm{NO} \rightarrow$ peroxynitrite $\Rightarrow$ OONO) (16). Peroxynitrite has a higher oxidative capacity than any other compound (16) (Figure 1). An important observation that links superoxide production to an increased level of ang II was obtained by Rajagopalan et al. (15). This study showed that arteries isolated from rats rendered hypertensive by the administration of a large amount of ang II $(270 \mu \mathrm{g} / \mathrm{kg})$ exhibited an impaired relaxation in response to acetyl- choline associated with an increased level of superoxidation. These alterations were corrected by pretreating the rats with Losartan (an ang II antagonist) or by treatment of vessels with liposome-encapsulated superoxide dismutase. In this study, hypertension was not felt to be responsible for stimulating superoxide production because norepinephrine infusion which raised blood pressure to similar levels as ang II was not accompanied by activation of superoxide. Additional studies of Rajagopalan et al. (15) showed that the stimulation of superoxide production in intact vascular segments was not related to the participation of xanthine oxidase, mitochondrial electron transport, cyclooxygenases, $\mathrm{NO}$ synthase and/or lipoxygenases because the response was unaffected by the administration of oxypurinol, rotenone, indomethacin, nitro-L-arginine-methyl ester (L-NAME) or nordihydroguayaretic acid (15). We have recently shown that superoxide can be stimulated by very low doses of ang II in swine because it increases plasma free isoprostanes. This effect was not seen in age-matched control animals that were not treated with ang II.

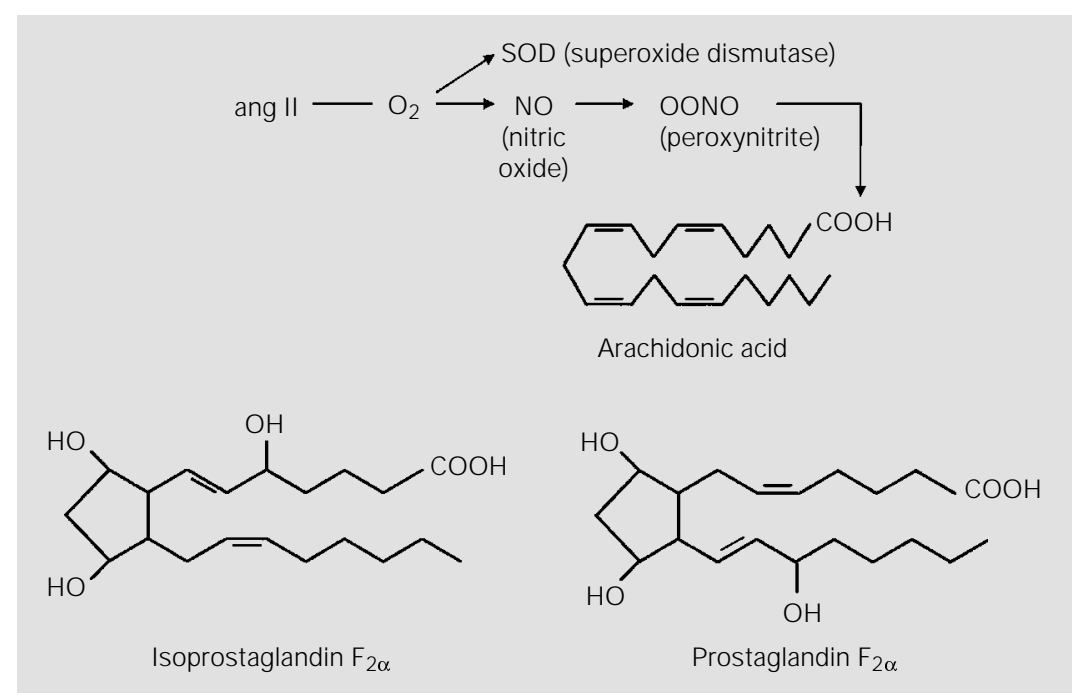

Figure 1 - Ang II induces superoxidation that can be neutralized by superoxide dismutase or could be bound to nitric oxide (NO) forming peroxynitrite. This compound oxidizes arachidonic acid forming isoprostaglandin $\mathrm{F}_{2 \alpha}$ which has a molecular constitution similar to that of prostaglandin $\mathrm{F}_{2 \alpha}$. 


\section{Endothelin}

Whether ET plays a role in mediating oxidative stress or is impacted upon by oxidative stress is not clear. Both ET production and NO synthesis can be stimulated by ang II $(17-19,27)$. In cultured endothelial cells inhibition of NO synthesis can stimulate the release of ET whose effects can be inhibited by Bosentan, a nonspecific ET antagonist $(28,29)$. NO can also regulate the vasoconstrictor effects of ET in vascular smooth muscle $(30,31)$. Supporting the hypothesis that both NO reduction and ET stimulation play a role in mediating the oxidative stress induced as a consequence of slow pressor responses to ang II are data showing that the acute hypertension induced by NO synthase inhibition can be attenuated by acute nonselective ETA/ETB antagonism $(32,33)$, whereas chronic NO synthesis inhibition (4 weeks) cannot be attenuated by acute ETA specific receptor antagonism (34). The role thatET plays in two kidney, one clip Goldblatt hypertension is not clear since oxidative stress, measured by production of isoprostanes, can induce the release of ET from smooth muscle cells (20-22). More directly we have recently observed that stimulation of oxidative stress by hypercholesterolemia in pigs evolves with a reduction in circulating $\mathrm{NO}$ and a significant increase in isoprostane and these changes can be obliterated by ET antagonism (35). This indicates the need to evaluate whether ET stimulates oxidative stress or whether oxidative stress stimulates production of ET. Caution should be taken in ascribing to ET a definitive role in experimental hypertension models because ET has been shown to have a potent diuretic and natriuretic effect at doses that do not lower glomerular filtration rate and this would antagonize any hypertensive effect $(36,37)$.

\section{Isoprostanes}

Isoprostanes are prostaglandin-like com- pounds produced by free radical-catalyzed peroxidation of arachidonic acid (38). Although there are 64 compounds that can be theoretically formed by peroxidation of polyunsaturated fatty acids, there are four classes of regioisomers currently found in mammals of which the most abundant is isoprostane $(39,40)$ (Figure 1). This compound is detected in plasma from healthy volunteers at levels of $35 \pm 6 \mathrm{pg} / \mathrm{ml}$ while urine contained $1.6 \pm 0.6 \mathrm{ng} / \mathrm{mg}$ of creatinine $(41,42)$. The levels of isoprostanes in plasma exceed by 10-20 times the levels of circulating prostaglandins (41). Isoprostane is increased about 200 times after oxidant injury inflicted by carbon tetrachloride $\left(\mathrm{CCl}_{4}\right)$ or the herbicide diquat $(41,42)$. It is also increased by smoking (43). There is evidence showing that, unlike prostaglandins, isoprostanes can be formed while the molecule of arachidonic acid is still esterified to phospholipids from where it can subsequently be released by phospholipases (44). This effect is clearly shown during the administration of $\mathrm{CCl}_{4}$ which increases the amount of isoprostane bound to liver phospholipids (by 40 times at $2 \mathrm{~h}$ ) which are then released into the circulation. Free isoprostane peaks in the circulation $8 \mathrm{~h}$ after the administration of $\mathrm{CCl}_{4}(45)$.

Arachidonic acid oxidation can also form iso- $\mathrm{D}_{2} / \mathrm{E}_{2}$ along with isothromboxane and isoleukotrienes. Although some of these compounds can be detected in tissue, they are not detected in the circulation under normal conditions (40). Another important issue is that isoprostane, the most abundant compound form in vivo, has been shown to be the most reliable index of lipid peroxidation (46). This provides an important tool to evaluate oxidative stress in vivo. A good review on this issue has been recently published by Morrow and Roberts (40).

Isoprostane can be locally produced in the kidney $(20,41)$. Administration of isoprostanes to the rat (low nanomole range) produces a potent renal vasoconstriction, reducing glomerular filtration rate and renal 
blood flow by $40-45 \%(20,41)$. These effects appear to be predominantly exerted on the afferent arteriole (20,21). Reckelhoff et al. (47) have shown that aging rats (22 months) exhibit a $50 \%$ reduction in glomerular filtration rate and 3 -fold increases in renal isoprostane when compared to young rats aged 3-4 months. Chronic treatment (9 months) with the antioxidant vitamin E normalizes renal isoprostane levels and improves glomerular filtration rate significantly (47). In rabbits and rats, isoprostane is also a potent pulmonary artery vasoconstrictor and causes bronchoconstriction in the rat lung $(48,49)$. In addition, isoprostane has been shown to induce a significant release of ET from bovine aortic endothelial cells (23).

An important characteristic concerning the biological activity of isoprostane is that the vasoconstrictor effects are blocked by the thromboxane receptor antagonist SQ29548 (20). However, several lines of indirect evidence (50) show that isoprostane interacts with a receptor in vascular smooth muscle that is distinct from the thromboxane receptor. Studies using molecular cloning strategies will be required to provide unequivocal proof of the existence of a unique isoprostane receptor.

\section{The relationship between sodium intake, plasma renin activity, extracellular fluid volume, and the development of oxidative stress}

The proposition that small increments in plasma concentrations of ang II are ultimately responsible for hypertension through the development of oxidative stress appears to be difficult to reconcile with the fact that during dietary sodium restriction the levels of plasma ang II are approximately 10-fold higher than those observed in subjects on a normal sodium diet (3). These conditions are illustrated in Figure 2 which also shows that a progressive increase in sodium intake produces a proportional volume expansion which exhibits a tight inverse correlation with the circulating levels of plasma renin activity. As shown in the figure, when the levels of extracellular fluid volume have achieved a maximal expansion with high sodium intake, plasma renin activity has virtually disappeared from the circulation. Guyton et al. (51) have suggested that this inverse relationship between fluid volume and plasma renin is extremely critical to maintain blood pressure within normal limits (see Figure 2). If this relationship is altered, for example, when the levels of plasma ang II are driven above those that correspond to a given level of either sodium intake or extracellular fluid volume, then the organism becomes susceptible to the development of hypertension through slow responses to ang II. This is shown in the figure where the levels of ang II have been "inappropriately" increased in animal models to levels A, B, C, and D, which induce proportional increments in mean arterial pressure (at the bottom of the

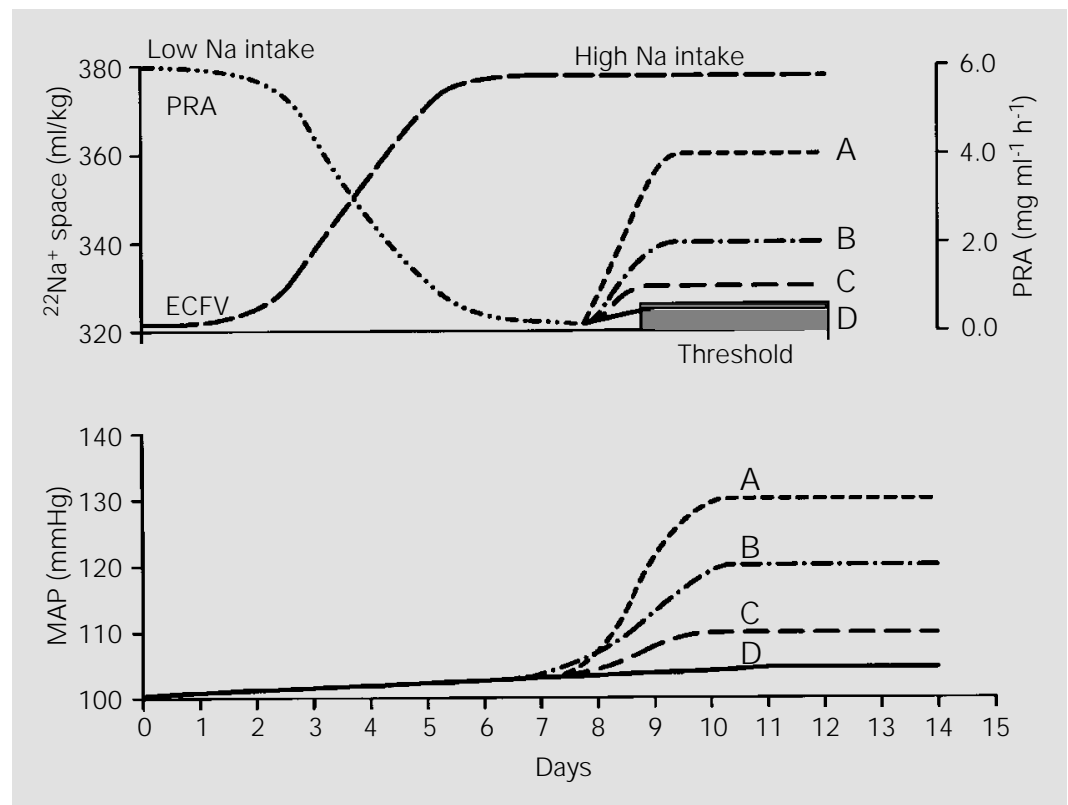

Figure 2 - Reciprocal changes in plasma renin activity (PRA) and extracellular fluid volume (ECFV) that occur when a low sodium diet is shifted to a high sodium diet (upper figure). This change contributes to the maintenance of mean arterial pressure (MAP) (lower figure). Infusion of different doses of ang II (A, B, and C) which maintain the plasma levels of this peptide inappropriately high with respect to ECFV produces hypertension. $D$, Smaller doses of ang II than (C) do not appear to alter MAP. 
figure). This assumption has led us to suggest that the circulating levels of angiotensin are "inappropriate" or "in excess" when compared with the level of extracellular fluid volume. This hypothesis is largely supported by the studies of DeClue et al. (52) who showed that when sodium intake is increased without allowing the circulating levels of angiotensin to be decreased because of continuous intravenous infusion, then the levels of blood pressure become strictly determined by the level of sodium intake. The observations of DeClue et al. (52) have many physiological and clinical implications. From the physiological standpoint, they demonstrate that hypertension through slow pressor responses can be induced by small elevations of circulating angiotensin that are inappropriate for the existing levels of extracellular fluid volume and, reciprocally, they show that hypertension can also be produced if the intake of sodium is inappropriate with respect to the existing levels of circulating ang II. The corollary of this conclusion is that the disruption of the reciprocal interaction between extracellular fluid volume and plasma renin activity (which serves to maintain blood pressure) appears to activate a permissive mechanism that renders oxidative stress susceptible to stimulation by ang II.

An alternative to this interpretation is the suggestion of the group of investigators directed by C. Wilcox that long-term effects of ang II are characterized by stimulation of aldosterone and sympathetic activity (53) and produce a simultaneous uncoupling of NO release and shear stress (54). These investigators have also found that the administration of a superoxide dismutase mimetic to spontaneous hypertensive rats normalizes mean arterial pressure (55).

As it is apparent, more studies are needed to unravel the specific pathways of oxidative stress that could affect blood pressure regulation.

The evidence examined in this review strongly favored the idea that metabolic products related to oxidative stress could play an important role in the development of hypertension with near normal levels of plasma renin activity.

\section{Acknowledgments}

Our thanks to Kristy Zodrow for the preparation of this manuscript.

\section{References}

1. World Health Organization (1999). International Society of Hypertension Guidelines for the Management of Hypertension. J ournal of Hypertension, 17: 151183.

2. DeWardener H (1990). The primary role of the kidney and salt intake in the aetiology of essential hypertension. Clinical Science, 79: 193-200.

3. Laragh J H (1984). The meaning of plasma renin measurements: renin and sodium volume-mediated (low renin) forms of vasoconstriction in experimental and human hypertension and in the oedematous states of nephrosis and heart failure. J ournal of Hypertension, 1: 141-150.

4. Brunner HR, Gavras H, Waeber B, Kershaw GR, Turini GA, Vukovich RA,
McKinstry DN \& Gavras I (1979). Oral angiotensin-converting enzyme inhibitor in long-term treatment of hypertensive patients. Annals of Internal Medicine, 90: 19-23.

5. Nelson EB, Harm SC, Goldberg M, Shahinfar S, Goldberg A \& Sweet CS (1995). Clinical profile of the first angiotensin II (AT-1 specific) receptor antagonists. In: Laragh J H \& Brenner BM (Editors), Hypertension, Pathophysiology, Diagnosis, and Management. Raven Press, New York.

6. Dickinson $\mathrm{CJ}$, Oxon DM, Lawrence J R \& Adelaide MB (1963). A slowly developing pressor response to small concentrations of angiotensin. Its bearing on the pathogenesis of chronic renal hypertension.
Lancet, I: 1354-1356.

7. McCubbin JW, DeMoura RS, Page IH \& Olmsted F (1965). Arterial hypertension elicited by subpressor amounts of angiotensin. Science, 149: 1394-1395.

8. Lever AF (1993). The fast and the slowly developing pressor effect of angiotensin II. In: Ian J, Robertson S \& Nicholls MG (Editors), The Renin-Angiotensin System. Gower Medical Publishing, London.

9. Munoz J M, Braun-Menendez E, Fasciolo J C \& Leloir LJ (1939). Hypertension: The substance causing renal hypertension. Nature, 144: 980-989.

10. Griendling KK \& Alexander RW (1994). Cellular mechanisms of angiotensin II action. In: Swales JD (Editor), Textbook of Hypertension. Blackwell Scientific Pub- 
lishing, Oxford.

11. Ames RP, Borkowski AJ, Sicincki AM \& Laragh J H (1965). Prolonged infusions of angiotensin II and norepinephrine and blood pressure, electrolyte balance and aldosterone and cortisol secretion in normal man and in cirrhosis with ascites. J ournal of Clinical Investigation, 44: 11711186.

12. Brown AJ, Casals-Stenzel J, Gofford S, Lever AJ \& Morton JJ (1981). Comparison of fast and slow pressor effects of angiotensin II in the conscious rat. American J oumal of Physiology, 241: H381H388.

13. Haas J A, Krier J D, Bolterman RJ \& Romero J C (1999). Low-dose angiotensin II increases free isoprostane levels in plasma. Hypertension, 34: 983-986.

14. Bean BL, Brown JJ, Casals Stenzel J, Fraser R, Lever AF, Miller J A, Morton J J, Petch B, Riegger AJ G, Robertson J IS \& Tree M (1979). The relation of arterial pressure and plasma angiotensin II concentration. A change produced by prolonged infusion of angiotensin II in the conscious dog. Circulation Research, 44: 452-458.

15. Rajagopalan S, Kurz S, Munzel T, Tarpey $M$, Freeman $B A$, Griendling $K K \&$ Harrison DG (1996). Angiotensin II-mediated hypertension in the rat increases vascular superoxide production via membrane NADH/NADPH oxidase activation. Contribution to alterations of vasomotor tone. J ournal of Clinical Investigation, 97: 19161923.

16. Pryor WA \& Squadrito GL (1995). The chemistry of peroxynitrite: a product from the reaction of nitric oxide with superoxide. American J ournal of Physiology, 268: L699-L722.

17. Chua BHL, Chua CC, Diglio CA \& Siu BB (1993). Regulation of endothelin-1 mRNA by angiotensin II in rat heart endothelial cells. Biochimica et Biophysica Acta, 1178: 201-206.

18. Kohno M, Horio T, Ikeda M, Yokokawa K, Fukui T, Yasunari K, Kurihara N \& Takeda T (1992). Angiotensin II stimulates endothelin-1 secretion in cultured rat mesangial cells. Kidney International, 42: 860-866.

19. Kawaguchi H, Sawa H \& Yasuda H (1990). Endothelin stimulates angiotensin I to angiotensin II conversion in cultured pulmonary endothelial cells. J ournal of Molecular and Cellular Cardiology, 22: 839-842.

20. Takahashi K, Nammour TM, Fukunaga M, Ebert J , Morrow J D, Roberts II LJ , Hoover RL \& Badr KF (1992). Glomerular actions of a free radical-generated novel prosta- glandin, 8-epi-prostaglandin $\mathrm{F}_{2 \alpha}$, in the rat. J ournal of Clinical Investigation, 90: 136141.

21. Fukunaga M, Makita N, Roberts II LJ , Morrow J D, Takahashi K \& Badr KF (1993). Evidence for the existence of $\mathrm{F}_{2}$-isoprostane receptors on rat vascular smooth muscle cells. American J ournal of Physiology, 264: C1619-C1624.

22. Fukunaga $M$, Yura T \& Badr KF (1995). Stimulatory effect of 8-epi-PGF $2 \alpha$, an $\mathrm{F}_{2^{-}}$ isoprostane, on endothelin-1 release. J ournal of Cardiovascular Pharmacology, 26: S51-S52.

23. Michael J R, Markewitz BA \& Kohan DE (1997). Oxidant stress regulates basal endothelin-1 production by cultured rat pulmonary endothelial cells. American J ournal of Physiology, 273: L768-L774.

24. Romero J C, Feldstein $A E$, RodriguezPorcel MG \& Cases-Amenos A (1997). New insights into the pathophysiology of renovascular hypertension. Mayo Clinic Proceedings, 72: 251-260.

25. Shanley PF (1996). The pathology of chronic renal ischemia. Seminars in Nephrology, 16: 21-32.

26. Kellerman PS (1996). Cellular and metabolic consequences of chronic ischemia on kidney function. Seminars in Nephrology, 16: 33-42.

27. Hennington $B S$, Zhang $H$, Miller $M T$, Granger J P \& Reckelhoff J F (1998). Angiotensin II stimulates synthesis of endothelial nitric oxide synthase. Hypertension, 31: 283-288.

28. Boulanger C \& Lüscher TF (1990). Release of endothelin from the porcine aorta: inhibition by endothelium-derived nitric oxide. J ournal of Clinical Investigation, 85: 587-590.

29. Saijonmaa O, Ristimaki A \& Fyhrquist F (1990). Atrial natriuretic peptide, nitroglycerine, and nitroprusside reduce basal and stimulated endothelin production from cultured endothelial cells. Biochemical and Biophysical Research Communications, 173: 514-520.

30. Hirata $Y$, Mtsuoka H, Kimura K, Suygimoto T, Hayakawa H, Suzuki E \& Sugimoto T (1991). Role of endothelium-derived relaxing factor in endothelin-induced renal vasoconstriction. J ournal of Cardiovascular Pharmacology, 17: S169-S171.

31. Lerman AJ , Sandok EK, Hildebrand J r FL \& Burnett J rJ C (1992). Inhibition of endothelium-derived relaxing factor enhances endothelin-mediated vasoconstriction. Circulation, 85: 1894-1898.

32. Qui Q, Engles K \& Baylis C (1995). Endothelin modulates the pressor actions of acute systemic nitric oxide blockade. J ournal of the American Society of Nephrology, 6: 1476-1481.

33. Richard V, Hogie M, Clozel M, Löffler B-M $\&$ Thuillez C (1995). In vivo evidence of an endothelin-induced vasopressor tone after inhibition of nitric oxide synthesis in rats. Circulation, 91: 771-775.

34. Fujita K, Matsumura $Y$, Miyazaki $Y$, Takaoka M \& Morimoto S (1995). Role of endothelin-1 in hypertension induced by long-term inhibition of nitric oxide synthase. European J ournal of Pharmacology, 280: 311-316.

35. Best PJ M, Lerman LO, Romero J C, Holmes J r DR \& Lerman A (1999). Chronic endothelin receptor antagonism preserves coronary nitric oxide activity in experimental hypercholesterolemia. Circulation, 99: 1747-1752.

36. Harris PJ, Zhou J, Mendelsohn FAO \& Skinner SL (1991). Haemodynamic and renal tubular effects of low doses of endothelin in anaesthetized rats. J ournal of Physiology, 433: 25-39.

37. Schnermann J, Lorenz J N, Briggs JP \& Keiser J A (1992). Induction of water diuresis by endothelin in rats. American J ournal of Physiology, 263: F516-F526.

38. Morrow JD, Harris TM \& Roberts II LJ (1990). Noncyclooxygenase oxidative formation of a series of novel prostaglandins: analytical ramifications for measurement of eicosanoids. Analytical Biochemistry, 184: 1-10.

39. Pryor WA, Stanley J P \& Blair E (1976). Autoxidation of polyunsaturated fatty acids: II. A suggested mechanism for the formation of TBA-reactive materials from prostaglandin-like endoperoxides. Lipids, 11: 370-379.

40. Morrow J D \& Roberts LJ (1997). The isoprostanes: unique bioactive products of lipid peroxidation. Progress in Lipid Research, 36: 1-21.

41. Morrow JD, Hill KE, Burk RF, Nammour TM, Badr KF \& Roberts II LJ (1990). A series of prostaglandin $\mathrm{F}_{2}$-like compounds are produced in vivo in humans by a noncyclooxygenase, free radical-catalyzed mechanism. Proceedings of the National Academy of Sciences, USA, 87: 93839387.

42. Morrow J D, Awad J A, Kato T, Takahashi K, Badr KF, Roberts II LJ \& Burk RF (1992). Formation of novel non-cyclooxygenasederived prostanoids ( $F_{2}$-isoprostanes) in carbon tetrachloride hepatotoxicity. An animal model of lipid peroxidation. J ournal of Clinical Investigation, 90: 2502-2507.

43. Morrow J D, Frei B, Longmire AW, 
Gaziano J M, Lynch SM, Shyr Y, Strauss WE, Oates J A \& Roberts II LJ (1995). Increase in circulating products of lipid peroxidation (F2-isoprostanes) in smokers. New England J ournal of Medicine, 332: 1198-1203.

44. Morrow J D, Awad J A, Boss HJ , Blair IA \& Roberts II LJ (1992). Non-cyclooxygenasederived prostanoids ( $F_{2}$-isoprostanes) are formed in situ on phospholipids. Proceedings of the National Academy of Sciences, USA, 89: 10721-10725.

45. Awad J A, Roberts II LJ , Burk RF \& Morrow J D (1996). Isoprostanes - prostaglandin-like compounds formed in vivo independently of cyclooxygenase: used as clinical indicators of oxidant damage. Gastroenterology Clinics of North America, 25: 409-427.

46. Morrow J D, Minton TA, Badr KF \& Roberts II LJ (1994). Evidence that the $F_{2-}$ isoprostane, 8-epi-prostaglandin $F_{2 \alpha}$, is formed in vivo. Biochimica et Biophysica Acta, 1210: 244-248.

47. Reckelhoff J F, Kanji V, Racusen LC, Schmidt AM, Yan SY, Morrow J , Roberts
II LJ \& Salahudeen AK (1998). Vitamin E ameliorates enhanced renal lipid peroxidation and accumulation of F2-isoprostanes in aging kidneys. American J ournal of Physiology, 274: R767-R774.

48. Kang KH, Morrow J D, Roberts II LJ , Newman J H \& Banerjee M (1993). Airway and vascular effects of 8-epi-prostaglandin $\mathrm{F}_{20}$ in isolated perfused rat lung. Journal of Applied Physiology, 74: 460-465.

49. Banerjee $M$, Kang KH, Morrow J D, Roberts LJ \& Newman J H (1992). Effects of a novel prostaglandin, 8-epi-PGF $2 \alpha$, in rabbit lung in situ. American J ournal of Physiology, 263: H660-H663.

50. Morrow J D, Minton TA \& Roberts II LJ (1992). The $F_{2}$-isoprostane, 8-epi-prostaglandin $F_{2 \alpha}$, a potent agonist of the vascular thromboxane/endoperoxide receptor, is a platelet thromboxane/endoperoxide receptor antagonist. Prostaglandins, 44: 155-163.

51. Guyton AC, Cowley J r AW, Coleman TG, Liard JF, McCaa RE, Manning J r RD, Norman J r RA \& Young DB (1973). Pretubular versus tubular mechanisms of renal hypertension. Excerpta Medica International Congress Series No. 302, 15-29.

52. DeClue JW, Guyton AC, Cowley AW, Coleman TG, Norman RA \& McCaa RE (1978). Subpressor angiotensin infusions, renal sodium handling and salt-induced hypertension in the dog. Circulation Research, 43: 503-512.

53. Luft $F C$, Wilcox CS, Unger $T$, Kuhn R, Demmert G, Rohmeiss P, Ganten D \& Sterzel RB (1989). Angiotensin-induced hypertension in the rat. Sympathetic nerve activity and prostaglandins. Hypertension, 14: 396-403.

54. Deng X, Welch WJ \& Wilcox CS (1996). Role of nitric oxide in short-term and prolonged effects of angiotensin II on renal hemodynamics. Hypertension, 27: 11731179.

55. Schnackenberg CG, Welch WJ \& Wilcox CS (1998). Normalization of blood pressure and renal vascular resistance in SHR with a membrane-permeable superoxide dismutase mimetic. Hypertension, 32: 5964. 